No 459

\title{
Conditional Cooperation: \\ Evidence for the Role of Self-Control
}

\author{
Peter Martinsson \\ Kristian Ove R. Myrseth \\ Conny Wollbrant
}

July 2010

ISSN 1403-2473 (print)

ISSN 1403-2465 (online) 


\title{
Conditional Cooperation: Evidence for the Role of Self-Control
}

\author{
Peter Martinsson, University of Gothenburg ${ }^{A}$ \\ Kristian Ove R. Myrseth, ESMT European School of Management and Technology ${ }^{B}$ \\ Conny Wollbrant, University of Gothenburg ${ }^{C}$
}

\begin{abstract}
When facing the opportunity to allocate resources between oneself and others, individuals may experience a self-control conflict between urges to act selfishly and preferences to act pro-socially. We explore the domain of conditional cooperation, and we test the hypothesis that increased expectations about others' average contribution increases own contributions to public goods more when self-control is high than when it is low. We pair a subtle framing technique with a public goods experiment. Consistent with our hypothesis, we find that conditionally cooperative behavior is stronger (i.e., less imperfect) when expectations of high contributions are accompanied by high levels of self-control.
\end{abstract}

Keywords: Self-control, Pro-social behavior, Public good experiment, Conditional cooperation.

JEL Classification: D01, D03, D64, D70.

\footnotetext{
Acknowledgments: Financial support from the Swedish Research Council (Vetenskapsrådet), the Jan Wallander and Tom Hedelius Foundation, and the Swedish International Development Cooperation Agency (Sida) to the Environmental Economics Unit at the University of Gothenburg is gratefully acknowledged. We are grateful to Tore Ellingsen, Katarina Nordblom and Robert Östling for helpful comments. Horacio Antonio Villegas Rivera provided excellent logistical support and Angela Maria Gonzales provided excellent research assistance.

A Department of Economics, University of Gothenburg, Box 640, 40530 Gothenburg, Sweden; Ph +46 31786 52 55; Fax +46 3178610 43; E-mail: peter.martinsson@economics.gu.se

${ }^{B}$ ESMT European School of Management and Technology, Schlossplatz 1, 10178 Berlin, Germany; Ph +49 (0) 3021231 1529; Fax +49 (0) 30212311281 E-mail: myrseth@esmt.org

${ }^{\mathrm{C}}$ Department of Economics, University of Gothenburg, Box 640, 40530 Gothenburg, Sweden; Ph +46 31786 26 15; Fax +46 3178610 43; E-mail: conny.wollbrant@economics.gu.se
} 


\section{Introduction}

The problem of self-control persists in many domains of private goods consumption. Well-known examples include smoking and dieting (see e.g., Frederick et al., 2002). ${ }^{1}$ Less is known, however, about the role of self-control in the domain of pro-social behavior, such as the voluntary provision of public goods (e.g., team work and environmental protection). ${ }^{2}$ The idea that problems of pro-social versus selfish behavior may be understood as problems of self-control has been explored only recently. Loewenstein (1996) suggests that selfish behavior may arise from visceral urges or drive-states, similar to those manifested in cravings for relief of hunger, pain, and sexual deprivation. O’Donaghue and Loewenstein (2007) argue that such selfish urges often conflict with the "colder," more abstract preferences for altruism, just as visceral urges for sweets could conflict with more abstract preferences for a fine figure or good health. This conceptualization of pro-social behavior mirrors the dual process modes of cognition from experimental psychology (e.g., Kahneman, 2003; Stanovich and West, 2000; Sloman, 1996). This perspective distinguishes between two modes of cognition. Roughly speaking, one is associative, effortless, "hot," and relies on parallel processing (our "emotional" self). The other is rule-based, effortful, "cold," and relies on serial processing (our "rational" self). The former is known as "System 1" and the latter "System 2."

Taken together, this implies that System 2 often is responsible for altruistic actions, while System 1 may be a driver of greed. The evidence to date, however, is relatively scarce, and much is indirect. For example, Pronin et al. (2008) show that decisions about others resemble decisions about "future selves," both classes of which contrast to decisions about less abstract "present selves." Curry et al. (2008) find that contribution to a public good is negatively correlated with discount rates; the more "patient" individuals are, the more they contributed to the public good. More recently, Martinsson et al. (2010) find both in a dictator and in a one-shot public good game direct support for the hypothesis that individuals with higher self-control act more pro-socially when conflict is "identified."

\footnotetext{
${ }^{1}$ For work on self-control and time inconsistency, see e.g. hyperbolic and quasi-hyperbolic discounting models by Strotz (1955) and Laibson (1997), the "planner-doer" model by Thaler and Shefrin (1981), and the dual-self model by Fudenberg and Levine (2006).

${ }^{2}$ Pro-social preferences have attracted significant research interest (e.g., overview in Fehr and Schmidt, 2006). Much work explores why individuals voluntarily contribute to charity (e.g., Andreoni, 2006; List, 2008). Work on the underlying motivations for pro-social behavior is extensive. For example, Bénabou and Tirole (2006) classify the motivations into three broad categories: intrinsic (e.g., pure altruism), extrinsic (i.e., monetary rewards), and image motivation (e.g., reputation). A similar discussion is found in Ariely et al. (2009). For early work on motivation, see for example Deci (1975).
} 
A prevalent form of pro-social behavior is that of "conditional cooperation" (e.g., Fischbacher and Gächter, 2010; Fischbacher et al., 2001; Keser and van Winden, 2000). Conditional cooperation means that individuals are willing to contribute to the public good when others contribute; individuals' contributions to the public good increase when the expectation of others' contributions increases. To study conditional cooperation, Fischbacher et al. (2001) applied the strategy method in a public good game. In the Fischbacher et al. (2001) design, participants are asked to conduct two tasks. Each participant reports how much they would unconditionally contribute to the public good (as in a traditional public goods experiment). Each participant also reports how much she would contribute given all possible integer combinations of other participants' average unconditional contributions. One may further classify participants into contributor types. Previous experiments have found conditional cooperators, whose contribution is positively correlated with expectation of others contributions, to represent the majority of participants, with free-riders representing a smaller fraction (e.g., Fischbacher and Gächter, 2010; Herrmann and Thöni, 2009; Kocher et al., 2008). ${ }^{3}$ However, most conditional cooperators tend not to completely match their expectations of others' contribution. Rather, they tend to contribute somewhat less than what they expect others to contribute. This empirical regularity is commonly referred to as imperfect conditional cooperation (e.g., Fischbacher and Gächter, 2010).

That an individual's target contribution to the public good increases when the expectation of others' contribution increases is relevant to self-control problems for two reasons. First, for the pro-social self of the individual (System 2), the cost of not contributing a positive amount increases when others' contributions increase. Thus the pro-social self should be willing to exert more costly self-control effort in pursuit of cooperative behavior. Second, with the increase in expectation about others' contributions, and the wish to match contributions, greed also becomes a relevant force. For the individual's greedy self (System 1), any contribution conflicts with self-interest. Because increasing expectations dictate larger contributions, the sensation of greed should increase as expectations increase. Indeed, were the individual not to believe that anyone else contributes, or were the individual a free-rider (who holds no pro-social preferences), then greed would not conflict with any wish to contribute. In this way, when System 2 is characterized by conditionally cooperative preferences, she wishes to increase her contribution when her expectation about others' contribution increases. System 1, however, prefers not to contribute anything. In response to

\footnotetext{
${ }^{3}$ For overviews of research on public goods experiments, see, e.g., Ledyard (1995) and Zelmer (2003).
} 
System 2's expectation about appropriate levels of contribution, System 1 exhibits greed, an impulse not to contribute. The more System 2 wants to contribute, the greater is System 1's impulse not to contribute. In response to System 1's impulse not to contribute, System 2 exercises self-control (or "willpower") to resist the impulse of greed. The outcome of the conflict will depend on the relative strengths of the two modes of cognition (willpower vs. greed). Thus, this leads us to hypothesize that the degree of conditional cooperation may depend on willpower, the lack of which could help explain imperfect conditional cooperation.

Our empirical approach is based on the two-stage model of self-control (Myrseth and Fishbach, 2009), according to which two conditions are necessary for successful restraint in the face of temptation. First, the individual identifies a conflict between indulging and pursuing a "higher-order goal," i.e., the most preferred alternative of System 2. Second, the individual employs self-control strategies, but only if conflict has been identified at the first stage (see Figure 1). Thus, self-control only is relevant when conflict has been identified. Such self-control strategies may take a variety of forms, and common examples include willpower (e.g., Baumeister et al., 1994) and pre-commitment (Thaler and Shefrin, 1981; Schelling, 1984).

\section{$>>$ Figure 1}

Because self-control is relevant to the decision to indulge only when the individual has identified a self-control conflict, a possible strategy for testing whether the problem of conditional cooperation versus selfish behavior resembles one of self-control is to investigate whether self-control is positively correlated with conditional cooperation when individuals have identified self-control conflict, but to a lesser extent when individuals have not.

In some instances, the question of conflict identification in the face of temptation is trivial. For example, the diabetic dieter knows that having even a single, tempting chocolate may incur major costs in terms of ill-health, while for a non-diabetic dieter facing the same chocolate the question is more ambiguous. Having the chocolate only will incur substantial costs if consumed extensively. Similarly, the pro-social individual may find that generally not contributing to his team of hardworking colleagues would threaten his self-image, but doing so on a few occasions is a more ambiguous matter. Tempting opportunities that incur but trivial costs when consumed in small amounts, but potentially significant costs when consumed extensively, are termed epsilon cost temptations by Myrseth and Fishbach (2009). 
Individuals identify self-control conflict in the face of epsilon cost temptation, they argue, if and only if two conditions are met: (a) the focal consumption opportunity must be viewed in relation to multiple additional opportunities, and (b) the decision maker must assume that similar choices are made for each opportunity. That is, considering whether or not to consume a chocolate will evoke self-control conflict in the non-diabetic dieter if the consumption opportunity is viewed in relation to future opportunities for chocolate consumption, but not if the consumption opportunity is viewed in isolation, as a singular event. Similarly, for the fairminded individual, the question of whether or not to contribute to the efforts of her hardworking colleagues may trigger self-control conflict if the choice of contributing is viewed in relation to future opportunities for cooperation, but not if viewed in isolation.

In the face of epsilon cost temptations, subtle framing manipulations may be sufficient to influence identification of self-control conflict. Myrseth and Fishbach (2010) found that presenting to participants a calendar of the current month with a grid, which separated the dates of the month, increased participants' consumption of potato chips compared to a calendar with no such grid (and thus no visual separation of the dates). They argue that the gridded calendar activated an isolated (versus interrelated) frame of the choice opportunity, thereby raising to the likelihood that participants isolated the date in question. In other words, participants were less likely to view the decision task in relation to similar future opportunities. Consequently, the gridded calendar reduced the likelihood that participants identified a conflict. Consistent with this argument, participants who viewed the calendar with the grid reported that they experienced less conflict during their decision to have chips or not than did those who viewed a calendar without a grid. Participants' trait ability to implement self-control strategies, measured by the Rosenbaum Self-Control Schedule ${ }^{4}$ (Rosenbaum, 1980) (henceforth, Rosenbaum score), was positively correlated with chips consumption for those who viewed the calendar without the grid (and who were more likely to identify conflict), but not for those who viewed the calendar with a grid (and who were less likely to identify conflict).

Our objective is to test the hypothesis that conditional cooperation, i.e., the contribution contingent on expectations of others' contributions, increases as self-control increases. To test

\footnotetext{
${ }^{4}$ The Rosenbaum score has been externally validated against several criteria (e.g., Rosenbaum and Rolnick, 1983) and measures individual's cognitive skills for exercising self-control in the face of temptation. Each participant is asked to respond to 36 statements using a 6-point Likert-scale (see appendix C). Each statement is graded from -3 to +3 (zero excluded). Thus, "perfect" self-control corresponds to +108 and "no self-control" to 108.
} 
this hypothesis, we combined with the framing manipulation from Myrseth and Fishbach (2009) the design of a public goods experiment by Fischbacher et al. (2001). The Fischbacher et al. (2001) design, and its reliance on the strategy method, is suitable since participants explicitly are asked to condition their decisions on their expectations of others' behavior. To capture individual's self-control, we used the Rosenbaum score. If conditional cooperation versus selfish behavior in the experiment represents a self-control conflict, one would expect that the interaction between participant's expectations about other's contributions and their trait self-control, as measured by Rosenbaum score, is positively correlated with contributions for those participants who view a calendar of the current month without a grid, but less so for those participants who view the same calendar with the grid.

\section{Experimental design and procedure}

\subsection{Experimental treatments}

Using a between-participant design, we employed three treatments - the isolated frame, the standard frame and the interrelated frame. The isolated versus interrelated frame was manipulated with the procedure from Myrseth and Fishbach (2010); participants viewed a calendar that displayed the present month, either containing a grid separating the dates or containing no such grid (see Appendix A). Furthermore, the date of the experiment was highlighted in grey in the calendar with a grid, but not in the calendar without. The standard frame contained no calendar and corresponds fully to the procedure of Fischbacher et al. (2001).

Because we expected participants who viewed a calendar with the grid to adopt an isolated frame of their decisions (and hence be less likely to identify self-control conflict), we refer to this treatment as the isolated treatment. In contrast, we expected participants who viewed a calendar without the grid to adopt a less isolated frame. Because their decisions thus would be viewed relatively more related to similar future decisions, we refer to this treatment as the interrelated treatment (higher likelihood of self-control conflict identification). We expected the interaction between participant's expectations about other's contributions and their trait self-control, as measured by Rosenbaum score, to be positively correlated with contributions in the experiment for participants who viewed a calendar of the current month without a grid, and less so for participants who viewed the same calendar with.

We denote the third treatment, without a calendar, as the standard treatment. Our main reason for including this control treatment relates to the validity of the Rosenbaum score. One 
might claim that any positive correlation between the interaction of the Rosenbaum and expectations about others' behavior with own contributions is due to the Rosenbaum score measuring pro-social preferences, and not due to the identification manipulation. If, however, we find in the standard frame a weaker correlation between the interaction and own contribution, we may rule out this possibility. Moreover, the standard treatment allows us to test whether our sample behaves similarly to those in previous work.

\subsection{The public good game}

We recruited student participants from various undergraduate classes at Escuela de Ingenieria de Antiouqia (EIA), Medellín, Colombia, 2008. We held six sessions, two for each treatment, with 24-28 participants per session. Nobody participated in more than one experimental session, and nobody was a student of mathematics, psychology, or economics.

We employed a standard linear public goods experiment. Each member was endowed with 20 tokens, which they were to divide between a public and a private good. The payoff for member $i$, measured in units of tokens, was calculated according to the payoff function

$$
\pi_{i}=20-c_{i}+0.4 \sum_{i=1}^{4} c_{i}
$$

where $c_{i}$ is individual $i^{\prime} s$ contribution to the public good. Contribution to the public good would yield to each member a marginal per capita return of 0.4 tokens. Each group consisted of four members. The choice of parameter values replicates the features of a public good since full contribution to the public good is Pareto optimal, while the dominant strategy is zero contribution to the public good - that is, to free-ride.

As in Fischbacher et al. (2001), participants were asked to make both unconditional and conditional contributions to the public good. In the case of unconditional contributions, they were asked simply how much they wished to contribute to the public good, as in a standard public goods game. However, in the case of conditional contributions, participants were asked how much they would like to contribute conditional on the average contribution of the other group members, ranging from 0 to 20 , rounded to the nearest integer.

Participants were randomly assigned to groups of four (from the same session). ${ }^{5}$ To make each decision incentive compatible, the unconditional contribution was the payoffrelevant decision for three randomly selected members. Using their average unconditional contribution, the contribution of the fourth member was given by her contribution table. Then,

\footnotetext{
${ }^{5}$ The selection was anonymous and hence no participant knew to which group she belonged.
} 
each member's monetary payoff would follow from equation (1). Each token in the experiment was exchanged for 750 Colombian pesos. The average earnings per participant were approximately 25,000 Colombian pesos (including a 5,000 peso show-up fee). ${ }^{6}$

The experiment was conducted as follows. For a given session, the experimenter first handed out written instructions to the participants. Subsequently, the experimenter read the instructions aloud. Participants next solved a series of control questions to help them fully understand the task. Thereafter, the experimenter distributed answer sheets to participants. For the isolated and interrelated treatments, the first page of the answer sheets contained a calendar that displayed the current month. For the standard treatment, however, there was no calendar. Thus, participants in the isolated and interrelated frames were subjected to the calendar manipulation immediately prior to making their allocation decisions. The experimenter then collected the answer sheets and distributed a questionnaire that contained the Rosenbaum score. Subsequently, participants answered some socio-economic questions, after which they were paid in privacy. The sessions lasted about 1.5 hours (for an outline of the procedure, see Appendix B).

\section{Results}

Table 1 provides a breakdown of the conventional contributor types (see e.g., Fischbacher et al., 2001) by treatment. Conditional cooperators represent approximately 50\% of participants. The remaining participants are classified as unconditional cooperators, humpshaped contributors, free-riders or others. The proportions appear roughly similar to those obtained in prior studies (e.g., Fischbacher et al., 2001).

>> Table 1

We expected that conditional contributions would depend on the interaction between identification of self-control conflict, which was induced by treatments, and success at the conflict stage (see Figure 1), which was measured by the Rosenbaum score. Specifically, we expected the Rosenbaum score to exhibit a weaker correlation with contribution in the isolated than in the interrelated treatment since participants in the isolated treatment less likely would identify self-control conflict.

\footnotetext{
${ }^{6}$ The exchange rate at the time of the experiment was approximately $1 \mathrm{USD}=1,762$ Colombian pesos.
} 
We hypothesized that success at the conflict stage would depend on the expectation of the average contribution of other group members (henceforth Others) and that it would interact with willpower. Conditional contribution preferences dictate that one's contribution increases if one's expectation of Others contribution increases. An increased contribution, however, implies a larger material cost to the individual, and thus a stronger impulse to act selfishly. By applying self-control, the individual may resist the impulse to act selfishly. Therefore, we expected the interaction term between Others and the Rosenbaum score to exhibit a stronger positive correlation with contributions when the likelihood of conflict identification was higher (interrelated treatment).

The regression analysis (reported in Table 2) supports our hypothesis. In each treatment, the variable Others is positive and significant at the one-percent level. Moreover, the interaction term between the Rosenbaum score and Others only is significant in the interrelated treatment, where we expected that identification of self-control conflict would be most likely.

The result is of economic significance; the marginal effect in the interrelated treatment of Others is: $0.215+0.006$ Rosenbaum score $;{ }^{7}$ The marginal effect evaluated at the mean of the Rosenbaum score (29.99) approximates to 0.395. That is, if contribution by others to the public good increases by one unit, then a participant increases contribution to the public good by 0.395 units. The marginal effect evaluated at one standard deviation (std.dev. $=19.94$ ) above the mean Rosenbaum score approximates to a marginal effect of $0.515,0.120$ units higher than that evaluated at the mean of the Rosenbaum score and corresponding to a $30 \%$ increase.

\section{>> Table 2}

Using the regression results, we plot predictions for three different levels of each independent variable. These levels are, "Low," "Mean" and "High." Conditional contribution is reported on the vertical axis, as a function of Rosenbaum score and Others by treatment. We set the threshold for classification of the Rosenbaum score at one standard deviation (such that "Low" is the mean value of the variable less one standard deviation, and "High" is the

\footnotetext{
${ }^{7}$ The marginal effect of Others is below 1 for all possible values of the Rosenbaum score. This means that our estimated model implies imperfect conditional cooperators. A higher Rosenbaum score brings participants closer to perfect conditional cooperators.
} 
mean plus one standard deviation). For Others, we set the corresponding levels for "Low," "Medium" and "High" at 4, 10, and 16, respectively. This provides nine classes ( $3 \times 3)$, for which we estimate the conditional contribution. We use the estimated model to predict values for each of the nine classes. ${ }^{8}$ The predicted contributions are presented in Figures 2-4 for the isolated, standard and interrelated treatments, respectively. Figures 2 and 3 show that conditional contributions increase as Others increases. This corresponds to the standard observation in public goods experiments. Notably, the figures show no association between conditional contributions and the Rosenbaum score. Figure 4, reveals a similar sensitivity to Others, i.e. to expectations about others' contributions. However, as hypothesized, and as confirmed in our regression, the effect of increasing Others appears stronger for higher levels of self-control. Indeed, the highest level of conditional cooperation in the Interrelated treatment, where we expected trait self-control to matter, is observed when both the Rosenbaum score and others' contributions are high, i.e., in the (High, High) cell.

$>>$ Figure 2

>> Figure 3

$>>$ Figure 4

\section{Discussion}

This paper joins a line of research that attempts to understand how individuals act on the basis of ostensibly conflicting preferences. While the economic literature on self-control has addressed this problem for quite a while (see Frederick et al., 2002, for a review), that on prosocial behavior has not. This paper follows Martinsson et al. (2010) in exploring the idea that the question of pro-social versus selfish behavior may represent one of self-control. As already established in the economic literature, cooperative behavior may be divided into two conceptually distinct categories, namely conditional versus unconditional cooperation (e.g., Fischbacher et al., 2001). Martinsson et al. (2010) explored the domain of unconditional cooperation. Using data from the same experiment, this paper examines conditional cooperation.

\footnotetext{
${ }^{8}$ Predictions are made with all parameters from the estimated model (Table 2), irrespective of significance levels.
} 
As Loewenstein (1996) proposes, selfish impulses may resemble "hot" urges for food or water, whereas pro-social preferences may be of "colder," more abstract nature. Therefore, as when the urge for sweets conflicts with the preference to stay slim, self-control, or "willpower," may determine behavior when selfish urges conflict with pro-social preferences. Martinsson et al. (2010) found evidence that higher self-control was associated with higher unconditional contribution for participants who had identified a self-control conflict. In line with these findings, this paper finds with the strategy method that higher self-control is associated with higher conditional contribution for participants who have identified a selfcontrol conflict. More specifically, we find that while the expectation of others' behavior indeed is a major predictor of contribution, it is a stronger predictor when individuals have high self-control. Furthermore, our results are of economic significance; the predicted conditional cooperation evaluated at the mean of the self-control score plus one standard deviation is $30 \%$ larger than the predicted contribution evaluated at the mean alone.

Evidence for the relationship between conditional cooperation and self-control is important not only because much cooperative behavior appears conditional in nature, but also because conditional cooperation bears important implications for strategic interaction in general. In strategic interaction, the choice of one player may affect the welfare of others in addition to that of herself. As we see in public goods games, expectations about others' contributions determine strategic behavior. If self-control determines conditional cooperation, self-control also determines players' strategic concerns. For example, in a two-period, two player game, the behavior of the first player may depend on that person's self-control as well as the expectations about the second person's behavior, which in turn may be determined by the second player's expectations about the self-control and expectations of the first player. Our results suggest a fruitful direction for the study of self-control in strategic interaction.

Furthermore, our findings help explain the empirical regularity of "imperfect conditional cooperation," that individuals, in fact, contribute less than what they think others will do. If individuals believe that they ought to match others' contribution, but at the same time are tempted to keep their endowment for themselves, limited self-control may cause them to contribute less than what that they believe they ought to contribute, or even contribute nothing at all. Our findings merit further investigation into possible field applications. The results suggest potential to boost pro-social behavior by helping individuals apply their own self-control resources. Such help could take the form of helping individuals improve their 
self-control, but it might also take the form of a simple reminder that their resources indeed are applicable and relevant to the task at hand. 


\section{References}

Andreoni, J. 2006. Philanthropy. S. C. Kolm, J. M. Ythier, eds. Handbook of the Economics of Giving, Reciprocity, and Altruism 2, North-Holland, Amsterdam, 1201-1269.

Ariely, D., A. Bracha, S. Meier. 2009. Doing good or doing well? Image motivation and monetary incentives in behaving prosocially. Amer. Econom. Rev. 99(1) 544-555.

Baumeister, R.F., T. F. Heatherton, D. M. Tice. 1994. Losing control: How and why people fail at self-regulation. Academic Press, San Diego, CA.

Bénabou, R., J. Tirole. 2006. Incentives and prosocial behavior. Amer. Econom. Rev. 96(5) $1652-1678$

Curry, O.S., M. E. Price, J. G. Price. 2008. Patience is a virtue: Cooperative people have lower discount rates. Personality and individual differences 44 780-785.

Deci, E.L. 1975. Intrinsic motivation. Plenum, New York, NY.

Fehr, E., K. M. Schmidt. 2006. The economics of fairness, reciprocity and altruism: Experimental evidence and new theories. Kolm, S., J.M. Ythier, eds. Handbook of the economics of giving, altruism and reciprocity 1, North-Holland, Amsterdam, 615-691.

Fischbacher, U., S. Gächter, E. Fehr. 2001. Are people conditionally cooperative? Evidence from a public goods experiment. Economics Letters 71(3) 397-404.

Fischbacher, U., S. Gächter. 2010. Social preferences, beliefs, and the dynamics of free riding in public good experiments, Amer. Econom Rev. 100(1) 546-665.

Frederick, S., G. Loewenstein, T. O’Donoghue. 2002. Time discounting and time preference: A critical review. Journal of Economic Literature 15(June) 351-401.

Fudenberg, D., D. Levine. 2006. A Dual-Self Model of Impulse Control. Amer. Econom Rev., 96(5) 1449-1476.

Herrmann, B., C. Thöni. 2009. Measuring conditional cooperation: A replication study in Russia. Experimental Economics 12(1) 87-92.

Kahneman, D. 2003. A perspective on judgment and choice: Mapping bounded rationality. American Psychologist 58 697-720.

Keser, C., F. van Winden. 2000. Conditional cooperation and voluntary contributions to public goods. Scandinavian Journal of Economics 102(1) 23-39.

Kocher M. G., T. Cherry, S. Kroll, R. J. Netzer, M. Sutter. 2008. Conditional cooperation on three continents. Economics Letters 101(3) 175-178. 
Laibson, D. I. 1997. Golden Eggs and Hyperbolic Discounting. Quarterly Journal of Economics 112(2) 443-477.

Ledyard, J.O. 1995. Public goods: A survey of experimental research. Kagel, J., A. Roth, eds. The Handbook of Experimental Economics. Princeton University Press, Princeton, NJ, 111-194.

List, J., 2008. Introduction to field experiments in economics with applications to the economics of charity. Experimental Economics 11(3) 203-212.

Loewenstein, G. 1996. Out of control: Visceral influences on behavior. Organizational Behavior and Human Decision Processes 65 272-292.

Martinsson, P., K. O. R. Myrseth, C. Wollbrant. 2010. Reconciling pro-social vs. selfish behavior: Evidence for the role of self-control. ESMT Working Paper No $10-003$, Berlin, Germany.

Myrseth, K.O.R., A. Fishbach. 2009. Self-control: A function of knowing when and how to exercise restraint. Current Directions in Psychological Science 18(4) 247-252.

Myrseth, K.O.R., A. Fishbach. 2010. Seeing self-control conflict: The problem of isolated vs. interrelated temptations. Working paper, the University of Chicago, Chicago, IL.

O’Donoghue, T., G. Loewenstein. 2007. The Heat of the Moment: Modeling Interactions Between Affect and Deliberation. Working paper, Cornell University, Ithica, New York. http//:www.arts.cornell.edu/econ/edo1/heat.pdf

Pronin, E., C. Y. Olivola, K. A. Kennedy. 2008. Doing unto future selves as you would do unto others: Psychological distance and decision making. Personality and Social Psychology Bulletin 34224 - 236.

Rosenbaum, M. 1980. A schedule for assessing self-control behaviors: Preliminary findings. Behavior Therapy 11 109-121.

Rosenbaum, M., A. Rolnick. 1983. Self-control behaviors and coping with seasickness. Cognitive Therapy and Research 793 - 97.

Schelling, T. 1984. Self-command in practice, in policy, and in a theory of choice. Amer. Econom. Rev. 74(2) 1-11.

Sloman, S. A. 1996. The empirical case for two systems of reasoning. Psychological Bulletin $113-22$.

Stanovich, K. E., R. F. West. 2000. Individual differences in reasoning: Implications for the rationality debate. Behavioral and Brain Sciences 23645 - 665.

Strotz, R. H. 1955. Myopia and inconsistency in dynamic utility maximization. Review of Economic Studies 23(3) 165-180. 
Thaler, R. H., H. M. Shefrin. 1981. An economic theory of self-control. The Journal of Political Economy 89(2) 392-406.

Zelmer, J. 2003. Linear public goods experiments: a meta-analysis. Experimental Economics 6(3) 299-310. 
Table 1. Absolute numbers and fractions of contributor type by treatment.

\begin{tabular}{lllll}
\hline Type & $\begin{array}{l}\text { Isolated } \\
\text { treatment }\end{array}$ & $\begin{array}{l}\text { Standard } \\
\text { treatment }\end{array}$ & $\begin{array}{l}\text { Interrelated } \\
\text { treatment }\end{array}$ & Total \\
\hline $\begin{array}{l}\text { Conditional } \\
\text { cooperators }\end{array}$ & 31 & 24 & 35 & 80 \\
& $51.36 \%$ & $50.00 \%$ & $47.17 \%$ & $50.96 \%$ \\
\hline Free-riders & 9 & 12 & 6 & 27 \\
& $16.07 \%$ & $25.00 \%$ & $11.32 \%$ & $17.20 \%$ \\
\hline Hump-shaped & 2 & 4 & 7 & 13 \\
contributors & $3.57 \%$ & $8.33 \%$ & $13.21 \%$ & $8.28 \%$ \\
& & & & 4 \\
\hline Unconditional & 2 & 0 & 2 & $2.55 \%$ \\
cooperators & $3.57 \%$ & $0.00 \%$ & $3.77 \%$ & 32 \\
& & & & $20.38 \%$ \\
\hline Others & 12 & 8 & 13 & 157 \\
& $21.43 \%$ & $16.67 \%$ & $24.53 \%$ & $100 \%$ \\
\hline Total & 56 & 48 & 53 & \\
& $100 \%$ & $100 \%$ & $100 \%$ & \\
\hline
\end{tabular}

Note. We classified a participant as a conditional cooperator either if the her own conditional contributions and expected contributions by others show a monotonic pattern with at least one increase or have a positive Spearman rank correlation at $1 \%$ significance level. Free-riders are those who conditionally contributed zero independently of the expected contributions by others. Humpshaped contributors have the same conditional contribution pattern as conditional cooperator up to some maximum point and then negative correlation based on the same criterion as for conditionally cooperating behavior.

Note. There are no statistically significant differences in distributions of types between treatments $\left(\mathrm{p}>.3\right.$; $\mathrm{Chi}^{2}$-test $)$. 
Table 2. Regression results.

\begin{tabular}{lc}
\hline $\begin{array}{l}\text { Dependent variable: Conditional } \\
\text { contribution }\end{array}$ & OLS \\
\hline Isolated treatment & 1.431 \\
& $(1.602)$ \\
Standard treatment & -0.705 \\
& $(-1.371)$ \\
Isolated treatment $\mathrm{x}$ Others & $0.360^{* * *}$ \\
& $(3.350)$ \\
Standard treatment $\mathrm{x}$ Others & $0.406^{* * *}$ \\
& $(4.699)$ \\
Interrelated treatment $\mathrm{x}$ Others & $0.215^{* * *}$ \\
& $(2.710)$ \\
Isolated treatment $\mathrm{x}$ Rosenbaum score $\mathrm{x}$ & -0.001 \\
Others & $(-0.380)$ \\
& \\
Standard treatment $\mathrm{x}$ Rosenbaum score x & 0.000 \\
Others & $(0.200)$ \\
& \\
Interrelated treatment $\mathrm{x}$ Rosenbaum score & $0.006^{* * *}$ \\
$\mathrm{x}$ Others & $(2.810)$ \\
Constant & $1.313^{* * *}$ \\
& $(3.768)$ \\
\hline R-squared & 0.177 \\
Number of observations & 3234 \\
\hline Note. $* * * \mathrm{p}<0.01, * * \mathrm{p}<0.05, * \mathrm{p}<0.1$. Standard errors \\
clustered at participant level. &
\end{tabular}


Figure 1. The two-stage model of self-control.

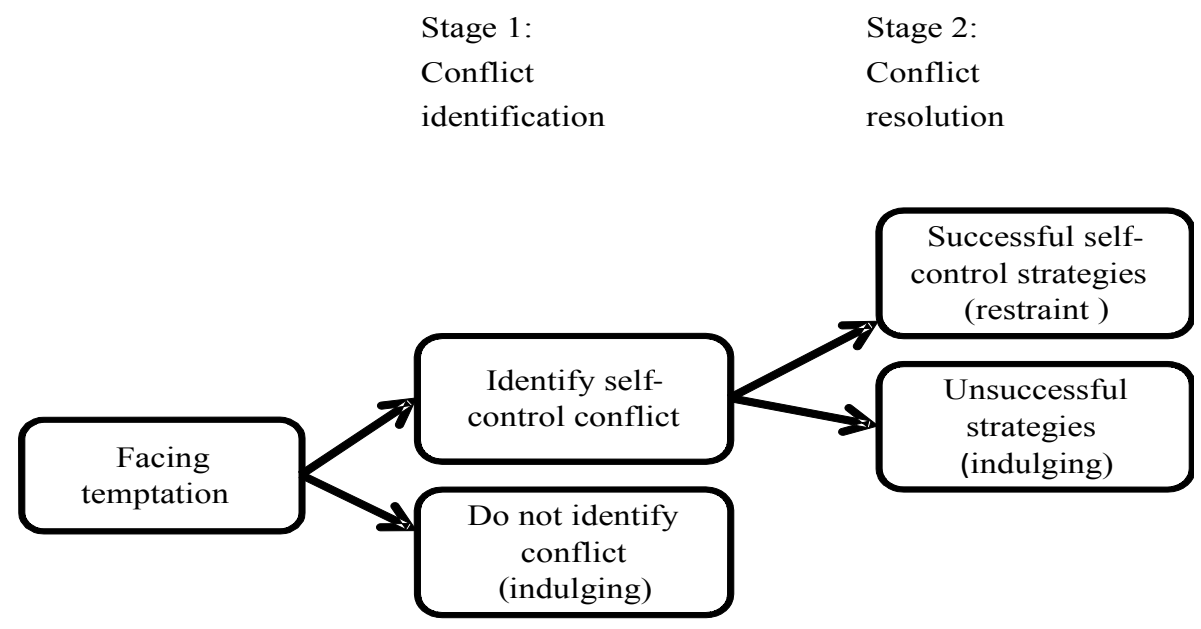

Source: Myrseth and Fishbach (2009). 
Figure 2. Conditional contribution by levels of self-control (Rosenbaum score) and expectation about others' average contribution (Others) in the Isolated treatment.

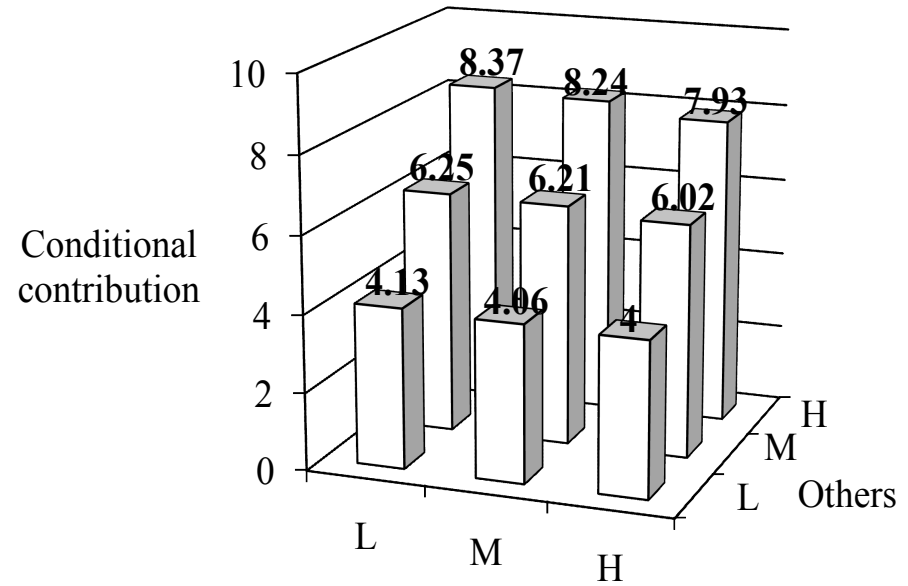

Rosenbaum score

Note. L, M, and H correspond to "Low," "Medium," and "High. The "Conditional contribution" axis plots predicted values of conditional contribution from the estimated model in Table 1. 
Figure 3. Conditional contribution by levels of self-control (Rosenbaum score) and expectation about others' average contribution (Others) in the Standard treatment.

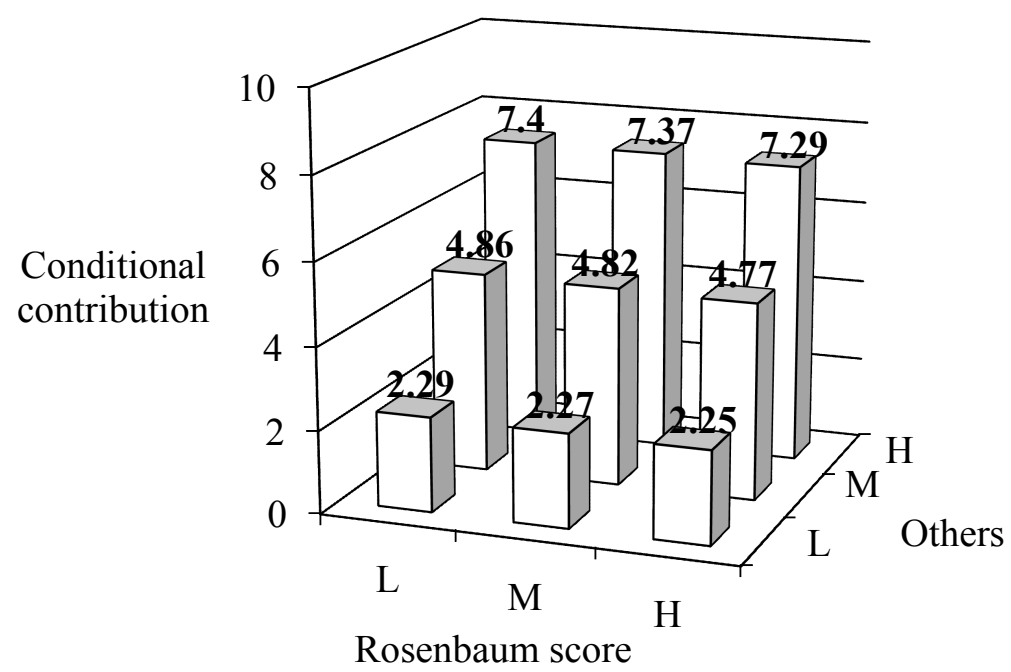

Note. L, M and H correspond to "Low," "Medium," and "High." The "Conditional contribution" axis plots predicted values of conditional contribution from the estimated model in Table 1. 
Figure 4. Conditional contribution by levels of self-control (Rosenbaum score) and expectation about others' average contribution (Others) in the Interrelated treatment.

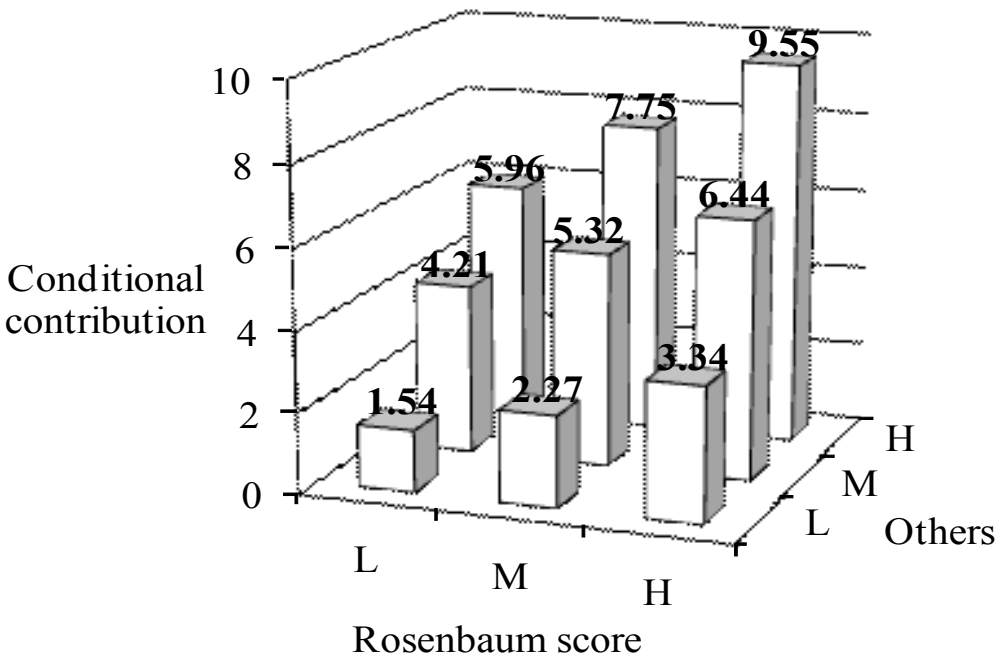

Note. L, M, and H correspond to "Low," "Medium," and "High." The "Conditional contribution" axis plots predicted values of conditional contribution from the estimated model in Table 1. 


\section{Appendix A: Calendars}

A.1 The isolated frame.

Before we continue with the experiment, please take a moment to consider this month's calendar:

\begin{tabular}{|c|c|c|c|c|c|c|}
\hline Sun & Mon & Tue & Wed & Thu & Fri & Sat \\
\hline & & & & 1 & 2 & 3 \\
\hline 4 & 5 & 6 & 7 & 8 & 9 & 10 \\
\hline 11 & 12 & 13 & 14 & 15 & 16 & 17 \\
\hline 18 & 19 & 20 & 21 & 22 & 23 & 24 \\
\hline 25 & 26 & 27 & 28 & 29 & 30 & 31 \\
\hline
\end{tabular}

What is today's date?

Note. The highlighted date is that on which the experiment was conducted. 
A.2 The interrelated frame.

Before we continue with the experiment, please take a moment to consider this month's calendar:

\begin{tabular}{|ccccccc|}
\hline Sun & Mon & Tue & Wed & Thu & Fri & Sat \\
& & & & 1 & 2 & 3 \\
4 & 5 & 6 & 7 & 8 & 9 & 10 \\
11 & 12 & 13 & 14 & 15 & 16 & 17 \\
18 & 19 & 20 & 21 & 22 & 23 & 24 \\
25 & 26 & 27 & & & & \\
& & & & & & \\
\end{tabular}

What is today's date? 


\section{Appendix B: Summary of experimental design and procedure}

I. General instructions

II. Treatment (one of i, ii or iii.)

i. $\quad$ Isolated treatment (calendar with grid)

ii. Standard treatment (no calendar)

iii. Interrelated treatment (calendar without grid)

III. Decision task (unconditional and conditional contribution)

IV. Belief elicitation. Participants answer how much they believe the other three group members contributed unconditionally on average.

V. Survey questions. Participants complete the Rosenbaum Self-Control Schedule (RSS). 